\title{
Materiais Didáticos Escolares e Injustiça Epistêmica: sobre o marco heteronormativo
}

\author{
Rosana Medeiros de Oliveira' \\ Debora Diniz' \\ 'Universidade de Brasília (UnB), Brasília/DF - Brasil
}

RESUMO - Materiais Didáticos Escolares e Injustiça Epistêmica: sobre o marco heteronormativo. As questões de gênero e sexualidade são pautas oficiais das políticas de educação em direitos humanos do Ministério da Educação. Implementar nas escolas públicas uma educação em direitos humanos requer a criação de condições para que as pessoas que não se enquadram nos marcos normativos de gênero e sexualidade possam viver livres da violência e da injúria. Uma transformação nos modos de representação e figuração sobre gênero e sexualidade é fundamental para a promoção da igualdade, sendo o principal desafio ético a desconstrução do marco da heteronormatividade, um registro discriminatório presente nas iniciativas pedagógicas do MEC, em particular nos livros e filmes didáticos. Neste artigo, a discussão desenvolve-se a partir da apresentação de duas pesquisas sobre os materiais didáticos distribuídos pelo MEC, livros e filmes, em que a heteronorma é um marco epistêmico.

Palavras-chave: Heteronormatividade. Igualdade. Discriminação. Educação. Materiais Didáticos.

\begin{abstract}
Pedagogical Tools and Epistemic Injustice: on the heteronormative framework. Gender and sexuality are official curriculum at the national agenda in human rights for the Ministry of Education. To implement a human rights perspective to education requires new conditions to allow people who are out of the hegemonic sexual frame to express themselves free of violence and injury. As a consequence, to transform the ways of represent and figurate gender and sexuality is essential to promote equality. This is the main ethical challenge to the heteronormative frame of the pedagogical initiatives of the Ministry of Education, mainly in the books and films distributed by the federal public policy. In this article the analysis is conducted from two different approaches on didactic materials distributed by the Ministry of Education, books and films, in which heteronormativity is the dominant episteme.

Keywords: Heteronormativity. Equality. Discrimination. Education. Didactic Materials.
\end{abstract}

Educação \& Realidade, Porto Alegre, v. 39, n. 1, p. 241-256, jan./mar. 2014.

Disponível em: <http://www.ufrgs.br/edu_realidade> 
Materiais Didáticos Escolares e Injustiça Epistêmica

\section{Introdução}

A criação de condições para o reconhecimento da diversidade e para combater os vários modos de hierarquização e precarização da vida, entre eles os de gênero e sexualidade, é um desafio que se coloca às políticas de educação. Os materiais didáticos distribuídos pelo Ministério da Educação (MEC), foco empírico deste artigo, compõem modos de representação da vida, ensinando a ver, sentir e pensar. Historicamente, no campo dos debates feministas e antirracistas, os modos de representação são considerados muito relevantes, pois atuam estabelecendo o âmbito do perceptível e do pensável, assim como constituem noções da vida humana reconhecível e suas fronteiras abjetas (Butler, 2010). Os mundos apresentados nos materiais didáticos afirmam definições políticas e históricas do que deve ser conhecido. Os enquadramentos de gênero e sexualidade nesses materiais são molduras, seleções, algo que ao mesmo tempo apresenta e descarta/elimina, demarcando o que é o sujeito humano e as vidas que serão reconhecíveis.

Analisar os enquadramentos que estabelecem os limites do humano - ou do sujeito hegemônico da representação - é exercício fundamental para as políticas sexuais e feministas em uma agenda de direitos humanos, de modo que as vidas que não são tornadas visíveis em sua vulnerabilidade, precariedade ou necessidade de proteção sejam objeto de atenção (Butler, 2010). As estruturas sociais de percepção nos dispõem ao cuidado com algumas populações - ou aos privilégios da norma - e indiferença sobre outras (Butler, 2010). Os modos de ordenamento do pensamento e da sensibilidade expõem diferencialmente as populações à violência. As pessoas que não se enquadram nos marcos normativos de gênero e sexualidade vivem sujeitas a uma série de constrangimentos e sob a ameaça da violência e da injúria ${ }^{1}$. A precarização destas vidas é uma condição politicamente induzida em parte pelas práticas e pelos discursos de formação do sujeito hegemônico e do sujeito diferencial. Como discute Didier Eribon (2008), uma série de esquemas de percepção e estruturas mentais sustenta a violência que recai sobre as pessoas fora da ordem androcêntrica e heterossexual. Esta é uma questão que tem se inserido na agenda política nacional, onde, por exemplo, diversas formas de violência contra as mulheres foram reconhecidas no marco legislativo (Lei Maria da Penha) e a violência contra os fora da ordem heterossexual é tema do Projeto de Lei 122, que estabelece a criminalização da homofobia (o PLC 122)².

Políticas anti-homofóbicas e antissexistas estão na pauta das agendas pedagógicas do Ministério da Educação. Entretanto, de acordo com duas pesquisas recentes (Lionço; Diniz, 2009; Oliveira, 2011), a heteronormatividade constitui o marco epistêmico ${ }^{3}$ da retórica pedagógica oficial dos livros didáticos aprovados e distribuídos pelo MEC, assim como da programação audiovisual na grade de Orientação Sexual da TV Escola ${ }^{4}$. De diferentes maneiras, os dois campos narrativos dessas pesquisas apresentam horizontes normativos distantes de uma 
agenda de redescrição das práticas de gênero e sexualidade, e de questionamento de suas formas de subalternização. A partir dessas pesquisas, este artigo desenvolve a tese de que uma transformação nos modos de representação e figuração sobre gênero e sexualidade é fundamental para a promoção da igualdade. Essa transformação tem como principal desafio ético o rompimento com o marco da heteronormatividade, um registro moral que fundamenta as iniciativas pedagógicas do MEC, em particular os livros e os filmes didáticos.

\section{Retórica Pedagógica Oficial 1: a heteronormatividade}

Entre livros e filmes didáticos, o marco heteronormativo não é desafiado pelas narrativas pedagógicas. O campo do possível não reconhece fissuras à heteronormatividade, assentada no binarismo de gênero e no silêncio sobre outras formas de experiência do corpo e da sexualidade. A pesquisa sobre os livros didáticos do Programa Nacional do Livro Didático (PNLD e PNLEM) analisou 67 dos 98 livros mais distribuídos e 25 dicionários distribuídos pelo Programa Nacional Biblioteca da Escola (PNBE) ${ }^{5}$. A pesquisa sobre a TV Escola analisou 88 de seus programas, em um universo de 122, os quais foram adquiridos pelo MEC entre 1996 e 2010, e são atualmente transmitidos pela TV Escola ou estão presentes nas videotecas escolares. Nos livros didáticos e dicionários, perseguimos diferentes expressões das narrativas sobre sexualidade - família, gênero, reprodução e saúde. Nas imagens em movimento, analisamos o que a TV Escola qualifica como sexualidade em seus programas $^{6}$. Na pesquisa sobre os livros didáticos, a questão da homofobia, definida como injúria contra os fora da lei de gênero, foi o objeto central, ao passo que a pesquisa sobre os filmes teve caráter descritivo sobre os dispositivos de gênero e sexualidade presentes nas narrativas?

A paisagem curricular nos livros e filmes reduz a sexualidade à heterossexualidade, e o diferencialismo de gênero é a lógica ordenadora dos corpos, das práticas e das sensibilidades ${ }^{8}$. Esses são textos e imagens que dão rosto ao currículo textual e audiovisual do MEC. O corpo tomado como geral e universal é heterossexual e se descreve sob a matriz de a sexualidade humana. O horizonte normativo das paisagens de gênero e sexualidade nos livros e filmes é a heterossexualidade. A heterossexualidade é naturalizada, insistentemente performada como prática pública em recorrentes cenas de beijos e abraços de casais heterossexuais, no caso dos filmes; e de prevenção às doenças sexualmente transmissíveis com exibição de pênis e vulvas, no caso dos livros. Tais paisagens não são alvo de qualquer censura ou estranhamento. Ao mesmo tempo, as vidas fora da lei do gênero não figuram nessas paisagens à exceção de três programas e de um exercício ambíguo sobre um filme em um livro de língua portuguesa ${ }^{9}$.

A heterossexualidade é tratada como uma natureza pressuposta em todo indivíduo. No caso dos livros didáticos, não há vida possível fora da norma: reprodução biológica e social se confundem nos corpos

Educação \& Realidade, Porto Alegre, v. 39, n. 1, p. 241-256, jan./mar. 2014.

243

Disponível em: <http://www.ufrgs.br/edu_realidade> 
Materiais Didáticos Escolares e Injustiça Epistêmica

generificados pelo binarismo. Nos filmes, as vidas fora da norma são ruídos a partir de um olhar que as situa como vidas de exceção. Um exemplo é a série chamada Alegria da vida: são reservados 10 segundos para a apresentação das vidas não heterossexuais em um contexto de uma hora e 20 minutos de programação ${ }^{10}$. Mas não é qualquer corpo fora da lei que rompe o enquadramento heteronormativo, apenas as homossexualidades. Nos filmes e nos livros, é apenas a sugestão da homossexualidade masculina que compõe o eventual e momentâneo rompimento à heteronorma, reforçando uma ordem sexista em que os homens (inclusive gays) mantêm o privilégio da visibilidade ${ }^{11}$. Outras possibilidades, como as lesbianidades, bissexualidades, transexualidades ou intersexualidades, não são sequer mencionadas no material analisado - à exceção dos programas Zimbábue e Em Outras Palavras (Oliveira, 2011).

No marco epistêmico da heteronormatividade, o diferencialismo de gênero é o horizonte naturalizante (macho-fêmea) que compõe as figurações da heterossexualidade nos livros e nos filmes. O gênero biológico é apresentado como uma das dicotomias fundamentais da natureza e replicado na ordem social pelas classificações mais básicas à vida de uma criança ${ }^{12}$. A estética das cores, por exemplo, não se desloca desse dobramento naturalizante nos livros de ensino fundamental: o rosa-azul colore o binarismo da diferença sexual. Sempre que se fala sobre gênero e sexualidade, humanos e não humanos são postos em um dos lados do par vagina-pênis ou rosa-azul ou qualquer um de seus variantes. Os textos e as imagens produzem binarismo de gênero em tudo e em $\operatorname{todos}^{13}$. A insistente afirmação de diferenças entre machos e fêmeas, meninos e meninas, homens e mulheres, extraterrestres machos e extraterrestres fêmeas, esses últimos personagens dos filmes, é um modo de materializar o ideal regulatório do gênero, delineando fronteiras corporais e subjetivas. O gênero é tratado como um fato corporal anterior à socialização e a qualquer ordem social.

Um exemplo curioso e recorrente nos filmes é a extensão do sistema de gênero às células reprodutivas, em que os códigos de gênero se aplicam aos gametas. Em animações, assim como em filmes que apresentam imagens microscópicas, ao óvulo e ao espermatozoide são atribuídas posições de feminilidade e masculinidade tais como as funções sociossentimentais e as marcações corporais gendradas. Uma "metafísica da diferença sexual" (Preciado, 2002) se opera e tudo reflete antagonismo sexual. Em diversas imagens-retóricas da programação, o gameta masculino age como um "bio-homem", e o feminino, como uma "bio-mulher" (Preciado, 2008) ${ }^{14}$. Uma política de gênero estendese às células e a cada parte do corpo, em que representações culturais dominantes de gênero são impostas (Martin, 1991). Esse tipo de fábula de gênero é performada em diversos filmes, nos quais os discursos sobre a natureza habilitam os sujeitos para a ocupação de diferentes espaços sociais ${ }^{15}$. O binarismo de gênero estabelece diferentes posições, 
performances e status para cada gênero biológico (sexo), legitimando desigualdades sociais, as quais se justificam como naturais.

Os livros e os filmes não questionam como as práticas de gênero subalternizam as feminilidades. Na contramão de uma perspectiva problematizadora das posições normativas de gênero, moraliza-se a feminilidade por meio dos discursos de prevenção à gravidez na adolescência ${ }^{16}$. A gravidez na adolescência é um evento que suspende as narrativas sobre sexualidade nos livros de biologia. A gravidez é um acontecimento científico e médico sobre a reprodução biológica. Nessa redescrição da gravidez como um tema moral e de saúde pública, as destinatárias do texto são as mulheres heterossexuais. Nem homens nem outras formas de vivência da sexualidade pelas mulheres se veem confrontados com o evento da gravidez na adolescência pelos livros. Esse esquadrinhamento da mensagem a um núcleo pacífico para a pedagogia do corpo nas escolas evita um enfrentamento explícito sobre práticas sexuais, prazer e proteção, e sequer menciona a questão do aborto clandestino ${ }^{17}$.

Os programas apresentam uma marca ainda mais severa no enquadramento da gravidez da adolescência como um signo da (hetero) sexualidade inadequada. A gravidez na adolescência é apresentada nos programas como signo de uma (hetero)sexualidade, em que as jovens mulheres arcam com estigmas e problemas de diversas ordens. As jovens são ensinadas que a gravidez é um problema que elas terão de aceitar se não estiverem dentro do script moral amor-casamento-reprodução. Além disso, outra operação de moralização da feminilidade se faz presente nos reiterados discursos dirigidos às jovens sobre saber se valorizar. Na programação isso significa a contenção do desejo erótico das mulheres, com o dispositivo amoroso atuando conjuntamente para regular a (hetero)sexualidade adequada, o momento certo para fazer amor em um campo de pedagogias endereçadas às mulheres. Um padrão de feminilidade é ensinado, e também a gramática em que a adolescente deve se expressar, na contramão de uma problematização do sistema de gênero e seus modos de subalternização. Tal moralização das figurações da feminilidade constitui uma retórica sexista, em que diferentes condições e possibilidades são ensinadas aos sujeitos.

De forma geral, portanto, as paisagens hegemônicas dos livros didáticos e da TV Escola ensinam aos sujeitos uma política dos corpos fundada na heterossexualidade e no diferencialismo de gênero - especialmente na ideia de diferença sexual e nas pedagogias de gênero que conferem diferentes espaços e possibilidades a homens e mulheres, como a moralização da feminilidade nos audiovisuais. A heterossexualidade e o diferencialismo de gênero são referências que constroem corpos e subjetividades pretensamente universais e neutros. A inserção eventual de identidades subalternizadas ocorre de forma periférica de acordo com as duas pesquisas, respondendo possivelmente às reivindicações das políticas de identidade. Em tal estratégia politicamente cor- 
Materiais Didáticos Escolares e Injustiça Epistêmica

reta, aparentemente se concede algum espaço a não heterossexuais, mas efetivamente essas pessoas são periferizadas quando se mostra que os corpos universais são héteros (Pocahy; Oliveira; Imperatori, 2009; Oliveira, 2011).

Esse tipo de resposta às demandas de visibilidade das políticas de identidade não questiona o marco heteronormativo presente nos modos de representação da norma. A heterossexualidade e o diferencialismo são normas silenciosas, mas bastante evidentes no corpo didático-ideal representado. Tal horizonte epistêmico, evidentemente, não está representando a heterogeneidade da vida social, mas performando mundos. Os mundos performados na programação inserem-se nos parâmetros normativos do sistema de gênero, apresentando identidades e modos de vida que figuram como naturais, invisíveis, universais: heterossexuais, homens-machos e mulheres-fêmeas. Tais posições são pensadas como naturais, e não como possibilidades que emergem em um campo social estruturado em hierarquias.

A retórica pedagógica dos livros didáticos e dos audiovisuais do MEC repete a estrutura de poder heteronormativa que ordena o espaço público. A esfera pública dos livros didáticos e da TV pedagógica do Estado afirma a heterossexualidade como local comum e público. Assim, o Estado, por meio dos materiais didáticos que distribui e disponibiliza, garante o direito à publicização e pedagogização da heterossexualidade na escola pública. As vidas não heterossexuais (e não heteronormativas) estão excluídas da cena pública dos livros didáticos e dos audiovisuais da TV Escola, sendo relegadas ao silêncio e à privatização de suas existências. O marco epistêmico heteronormativo desses materiais retira as vidas fora da lei do gênero do campo de existências possíveis, públicas e legítimas. Essa ordem epistêmica constrói os limites do pensável e do enunciável em um universo que marginaliza as vidas fora da heteronorma. Além disso, nesses materiais, a heteronorma apresenta-se tramada em discursos naturalizantes e psicologizantes, despolitizando o campo das questões de gênero e sexualidade.

\section{Retórica Pedagógica Oficial 2: a psicologização e biologização do sistema de gênero}

Nos materiais analisados nas duas pesquisas, o marco epistêmico da heteronormatividade está envolvido por uma retórica psicologizante e biologizante que despolitiza as agendas de gênero e sexualidade, tratando-as como questões individuais ou mesmo naturais. Esses dois mecanismos retóricos se norteiam por uma referência psi e naturalizante e supõem indivíduos isolados, fazendo escolhas pessoais ou agindo de acordo com sua natureza biológica. O indivíduo livre ou o indivíduo escravo da genética somente superficialmente parecem ser dois extremos morais em torno da sexualidade: são figuras complementares para silenciar demandas por reconhecimento como questões de justiça. Nos dois mecanismos retóricos, as questões relativas a gênero e sexuali-

246 Educação \& Realidade, Porto Alegre, v. 39, n. 1, p. 241-256, jan./mar. 2014 Disponível em: <http://www.ufrgs.br/edu_realidade> 
dade são pensadas como decorrentes de processos individuais, seja em termos de determinação biológica, seja em termos de interioridade psicológica. O discurso sobre os atos dos indivíduos isoladamente - como membros da espécie ou como sujeitos psicológicos - os torna responsáveis por suas condições, ou mesmo pela origem de seus problemas.

A retórica psicologizante atribui ao indivíduo a origem de suas práticas e desejos. Gênero e sexualidade são tratados como questões interiorizadas e privadas, que dizem respeito à vontade do próprio sujeito ou à sua vida psicológica individual. Nos livros e filmes, os discursos sobre gênero e sexualidade são construídos em um horizonte psicologizante de autodesenvolvimento individual ou relacional ${ }^{18}$. Nesse campo não há nenhuma discussão sobre como as relações sociais e hierarquias do sistema de gênero constituem nossos modos de ser. Não se debate a sociabilidade fundante de nossas existências, a noção de que somos seres que vivem em redes de dependência, nem o fato de que as possibilidades de individuação e singularização são gestadas em um campo social que não escolhemos e que nos precede (Butler, 2010). É o indivíduo que emerge ora como sujeito de criação, ora como escravo de seu próprio código genético.

Há uma pequena variação na abordagem biologizante dos livros e dos filmes. Nos livros didáticos, a sexualidade é um tema restrito à biologia, portanto referente à natureza humana. Para falar do corpo sexuado, a ordem narrativa é científica, mas a moral sexual é a reprodução biológica. O público não é mais o das crianças que performam gênero pelas cores, mas de adolescentes que localizam seus corpos e sexualidades na gramática reprodutiva do nascimento de bebês. Sexo e reprodução confundem-se na naturalização da procriação heterossexual. Isso também ocorre nos audiovisuais, mas estes apresentam suas discussões sobre (hetero)sexualidade em campos disciplinares mais variados, e com endereçamento tanto para crianças, como para jovens ${ }^{19}$. Nos audiovisuais, as figurações de gênero e sexualidade são tratadas como acontecimentos essencialmente biológicos, em que a ordem da natureza se expressa. A natureza sexual que se atualiza nos indivíduos é a heterossexualidade, assim como as posições de gênero normativas. Paralelamente a essa retórica naturalizante, pedagogias de gênero são performadas em livros e filmes, ensinando os modos de vida e as práticas de gênero e de sexualidade - diga-se, heterossexualidade - adequadas. A retórica biologizante faz as pedagogias de gênero e sexualidade em ação aparecerem como natureza (hetero)sexual.

As formulações biologizantes da natureza sexual e a afirmação da evidência biológica das posições binárias de gênero têm como efeito imediato o ocultamento das pedagogias envolvidas. Não se fala de sexualidades, mas de natureza, um marco essencialista que silencia a diversidade por meio da norma heterossexual implícita. A retórica biologizante faz os modos de vida apresentados na programação parecerem naturais e apriorísticos, invisibilizando as pedagogias em ação e os 
Materiais Didáticos Escolares e Injustiça Epistêmica

modos de inteligibilidade pressupostos. A natureza e a natureza biológica são apresentadas como forças espontâneas e inocentes, anteriores a qualquer intervenção humana. Uma moralidade transpõe-se para a natureza, de forma que a autoridade das práticas sociais (heterocentradas) coloniza o impreciso discurso sobre o natural. Os discursos de moralização da feminilidade, assim como da (hetero)sexualidade adequada, trabalham nesse tropo naturalizante, em que ser completamente natural corresponde a ser moralmente pleno (Diniz, 2001).

As figurações da sexualidade e do gênero desses materiais performam um mundo em que diferenças e subalternidades são lidas como parte da vida psicológica. As hierarquias que dizem respeito às posições normativas de masculinidade e feminilidade são tratadas como questões de "autoestima”, "maturidade”, “diálogo”, "autoaceitação" (Oliveira, 2011). Ou seja, as práticas de gênero são pensadas como campos psicológicos e não como práticas sociais e políticas. O resultado é que os problemas encenados são tratados como questões psicologicamente administráveis, na completa carência de um ponto de vista ético-político que compreenda e questione o sistema de gênero. A retórica psicologizante não é um modo de interpretação, mas a própria trama na qual as questões de gênero e sexualidade são formuladas. Ou seja, as imagens e os discursos dos materiais configuram horizontes existenciais, em que as questões de gênero e sexualidade têm um molde psicologizado. A sexualidade é construída como um espaço psicológico que é ou individual ou relacional, e o par heterossexual figura como a unidade pressuposta $^{20}$. A linguagem psicológica não visibiliza as condições sociais de produção dos corpos, dos desejos, da eroticidade, de modo que não há uma agenda política de direitos expressa nesses materiais, mas sim um olhar despolitizante que reforça a ideia de que gênero e sexualidade são questões privadas, e não questões políticas e públicas.

Nesses materiais, as vidas são mostradas em sua individualidade ou em sua biologia, e nunca como individuações social e politicamente gestadas. Em tais retóricas, a heterossexualidade e o diferencialismo de gênero operam sem qualquer conceituação explícita: aparecem como a ordem natural da vida psicológica e biológica. Essas paisagens curriculares constituem uma verdadeira gramática para inteligibilidade do mundo e para a autoexpressão, em uma despolitização das práticas de gênero e sexualidade. Nesse cenário, as subjetividades e sexualidades não hétero não aparecem no horizonte do possível. E a violência de que são alvo não é tematizada, sendo-lhes retirado o direito à existência na esfera pública.

\section{Heteronormatividade e Violência Sexista e Homofóbica: faces de um problema escolar}

Para entender a violência sexista e homofóbica - seja física, seja pela injúria -, é preciso atentar para suas condições de produção. Os assassinatos, espancamentos e insultos sexistas e homofóbicos são

248 Educação \& Realidade, Porto Alegre, v. 39, n. 1, p. 241-256, jan./mar. 2014 Disponível em: <http://www.ufrgs.br/edu_realidade> 
gestados em um horizonte epistêmico específico, em que um modo de inteligibilidade dos corpos e da vida se afirma. A heteronorma parece quase inofensiva, apenas um campo de inteligibilidade em que a heterossexualidade e as posições normativas de gênero são dadas a priori. Já a violência física ou a injúria homofóbica e sexista são normalmente vistas como inaceitáveis e abusivas. Entretanto sexismo e homofobia são gestados em um campo heteronormativo que resiste tanto em reconhecer a homofobia como violação de direitos humanos quanto em potencializar a escola como espaço de transformação social.

O neologismo bullying, por exemplo, é um dos sinais mais contundentes desta dificuldade ético-política: tratar a violência sexista e homofóbica nas escolas como um problema relacionado às práticas sociais normativas de gênero e sexualidade, que diz respeito a agendas políticas e de direitos, em vez de tratá-la como uma questão individual. As recorrentes injúrias contra crianças e adolescentes entendidas como fora da lei do gênero tornaram-se bullying no jargão escolar. Ao descrever a injúria homofóbica ou sexista como bullying, neutraliza-se a questão da sexualidade, como se aquela fosse uma violência sem alvo no corpo engendrado e sexuado. O bullying é parte de uma gramática psicologizante, em que práticas e sensibilidades socialmente gestadas são pensadas como originadas em sujeitos individuais (ou no campo psicologizante estendido, a família). Indivíduos, isoladamente ou em grupo, aparecem como figuras disfuncionais, patológicas. Entretanto, quando alguém expressa uma injúria homofóbica ou sexista - por exemplo, veado, sapata, vadia -, não se está inaugurando uma fala, um afeto, nem um modo de pensar. Não se trata de uma psique violenta, agressiva, mas sim de uma prática socialmente gestada (a injúria sexista ou homofóbica), segundo a qual algumas vidas valem menos do que outras; trata-se de performar hierarquias e diferenças, de diminuir e constituir o outro.

A injúria sexista e homofóbica é gestada em um horizonte (epistêmico) de hierarquias de gênero e sexualidade. Sua expressão não é apenas do indivíduo que a utiliza. Ela manifesta um campo de normas e de valores do sistema de gênero. Tratar a injúria (ou outras formas de violência) sexista ou homofóbica como bullying, como uma manifestação arbitrária de uma psique violenta per si, não nos permite perceber que ela só pode emergir em um campo de normas e ordenações sociais do sistema de gênero. Ou seja, a retórica do bullying faz as manifestações homofóbicas e sexistas serem tratadas como uma violência de indivíduos, apolítica, desligada das normas sociais que estabelecem quais vidas são verdadeiramente dignas de respeito e de existência pública.

O marco epistêmico da heteronormatividade é um dispositivo hierarquizante cujas regras naturalizantes (tidas como autoevidentes) tornam o que a elas escapa um erro, uma exceção, uma abjeção. Esse sistema de inteligibilidade é o horizonte sobre o qual emergimos como sujeitos, e em que aprendemos a sentir, pensar, falar, existir ${ }^{21}$. Esse marco rege a inteligibilidade dos corpos, estabelece o que é cognoscível, condiciona as formas de reconhecimento dos corpos por meio de carac-

Educação \& Realidade, Porto Alegre, v. 39, n. 1, p. 241-256, jan./mar. 2014.

249

Disponível em: <http://www.ufrgs.br/edu_realidade> 
Materiais Didáticos Escolares e Injustiça Epistêmica

terísticas que serão consideradas óbvias, visíveis e, até mesmo, presumíveis. Os marcos epistêmicos são normas de inteligibilidade, são esquemas de percepção pelos quais conhecemos um corpo e pelos quais reconhecemos os modos de vida considerados naturais ou normais. Se a heteronormatividade coloniza os modos de representação dos materiais didáticos, as paisagens curriculares não ensinam que corpos e subjetividades podem ser vividos e pensados de outras maneiras, isto é, fora dessa norma. A heteronormatividade atua não apenas sobre heterossexuais, bio-homens e bio-mulheres, mas sobre todas as pessoas sob seu regime: em vez de ser vista como uma identidade construída e não natural, apresenta-se como um lugar de prestígio, uma posição de poder não nomeada, um lugar confortável de onde se pretende ver os que serão considerados outros, diferenças, exceções ${ }^{22}$.

Estar fora da heteronorma é uma condição de vulnerabilidade ainda não devidamente enxergada nas políticas públicas de educação. Os discursos sobre orientação sexual e sexualidade nos materiais didáticos operam como engrenagens que reafirmam a ordem heterossexual e o binarismo de gênero. $\mathrm{O}$ combate à ameaça da violência e da injúria sexista e homofóbica deve atentar para os modos de representação. A escola é um espaço privilegiado para essa operação de transformação, cujos alvos não devem ser apenas situações e casos concretos, mas os marcos epistêmicos que estabelecem o que é uma vida e como ela deve ser vivida. Na ordem heteronormativa, a realidade é dividida entre um nós (hétero) e um outro (não hétero), de forma que o outro é sempre tornado extremamente e incomodamente visível quando representado. Ao mesmo tempo, esse outro desaparece como realidade, é tornado irrelevante e/ou particular pela norma, não necessitando de representação - dado seu suposto caráter de exceção. A incômoda e eventual visibilidade desse outro decorre diretamente da norma, supostamente natural, da heterossexualidade. Essa visibilidade dos fora da lei do gênero, vista como extrema, se dá porque a ordem social heteronormativa pressupõe a heterossexualidade e toda diferença passa a ter de ser anunciada e explicada - a diferença não hétero raramente figura apenas como uma paisagem do possível.

O marco epistêmico da heteronormatividade indica um mutismo curricular para com as vidas fora da lei do gênero e os modos de subalternização das mulheres. Para que os materiais didáticos ensinem a ver, em vez de reproduzirem silêncios que oprimem, será preciso atentar para os modos de representação, de modo a permitir o reconhecimento e combater as formas de hierarquização implicadas nas normas de inteligibilidade apresentadas. Problematizar a norma, ou seja, provocar os marcos epistêmicos a partir dos quais se apresentam os corpos e as vidas, é um modo de refletir sobre as normas excludentes que constituem os campos de reconhecibilidade; é também questionar, por exemplo, por que se reage com indiferença à violência que recai sobre algumas vidas (Butler, 2010). As formas de hierarquização e subalternização das vidas fora da lei do gênero e das mulheres precisam ser enfrentadas a

250 Educação \& Realidade, Porto Alegre, v. 39, n. 1, p. 241-256, jan./mar. 2014 Disponível em: <http://www.ufrgs.br/edu_realidade> 
partir de um questionamento das normas de inteligibilidade que têm estabelecido os parâmetros do que é uma vida humana.

\section{Considerações Finais}

Na retórica pedagógica oficial dos livros didáticos e dos audiovisuais, o marco epistêmico da heteronormatividade (e o diferencialismo de gênero nele implicado) reitera a injustiça social que demanda que essas vidas fiquem escondidas, em segredo ou em um lugar subalternizado. As vidas fora da lei do gênero são marginalizadas da cena pública dos livros didáticos e da TV Escola, figurando como vidas de exceção, vidas que deveriam se manter no silêncio, diminuídas, talvez no armário - no armário curricular. Ou seja, a esfera pública educativa apresenta-se heteronormativamente estruturada - ao menos nesse campo de materiais didáticos -, e as vidas não heteronormativas são mantidas reclusas no armário da invisibilidade.

A heteronormatividade constitui um padrão hegemônico de representação dos corpos que não é facilmente percebido, já que dado como única possibilidade natural, legítima e autoevidente. Entender a heteronormatividade como marco epistêmico evidencia que há uma norma heterossexual escondida sob o discurso da neutralidade, da objetividade e da universalidade. Além disso, na lógica heteronormativa, o diferencialismo de gênero faz pensar os seres a partir da grade binária macho e fêmea, naturalizando e performando um mundo de posições masculinas e femininas, sob o discurso da objetividade e da universalidade empírica dessa distinção. Contudo tal sistema de posições, mais do que representar a realidade, performa mundos binários, construindo e reforçando diferenças e hierarquias.

Estes dois grandes campos de materiais didáticos distribuídos pelo MEC, os livros didáticos e os audiovisuais da TV Escola (especialmente a programação sobre gênero e sexualidade), são um exemplo de como as normas da heterossexualidade e do diferencialismo de gênero constituem modos de inteligibilidade que reduzem tudo o que escapa à sua ordenação ao campo da diferença menor, da particularidade, da exceção. Nos livros didáticos e nos materiais audiovisuais, o corpo hétero, masculino ou feminino, é o corpo universal, em uma retórica normativa na qual os corpos alheios a esse marco figuram como corpos de exceção. Privilegiar heterossexuais - bio-homens e/ou bio-mulheres - como sujeitos universais é uma injustiça epistêmica, pois mantém o mecanismo central de sustentação dos sistemas de hierarquização de gênero e sexualidade. A norma que orienta os modos de ver e compreender os corpos e a vida reitera um sistema de injustiças, de diferenças subalternizantes, sob o disfarce da universalidade e/ou da natureza.

As retóricas pedagógicas oficiais são situadas em um sistema de hierarquias de gênero e produzem o mundo que deverá ser reconhecido como natural, hegemônico e ideal. Na vida escolar, onde o ambiente 
Materiais Didáticos Escolares e Injustiça Epistêmica

de hostilidade e vigilância da ordem (hetero)sexual é patente (Borrillo, 2009; Junqueira, 2010; Louro, 2000), o marco epistêmico da heteronormatividade presente nos materiais didáticos do MEC reforça essa ordem. Os modos de falar e ensinar sobre o mundo presentes nesses materiais corroboram as fronteiras de gênero e sexualidade que os insultos e outros modos de violência vigiam. E, na medida em que a heteronormatividade (e o diferencialismo de gênero implicado) constitui um marco epistêmico, homofobia e sexismo têm o ambiente propício para se desenvolver.

A injustiça social das hierarquizações e subalternizações de gênero e sexualidade se faz acompanhar da injustiça epistêmica da heteronormatividade presente nos modos de representação hegemônicos dos materiais distribuídos pelo MEC. A homofobia e o sexismo, tão presentes na vida escolar, são formas de hierarquização e subalternização que mantêm a ordem (hetero)sexual. A episteme heteronormativa da retórica oficial dos materiais didáticos do MEC não apresenta outros horizontes do possível (fora da ordem hétero), nem questiona as práticas excludentes e marginalizadoras das mulheres e das vidas fora da lei do gênero. Heteronormatividade e violência sexista e homofóbica são polos de um mesmo campo de inteligibilidade dos corpos. Há uma injustiça intolerável: as normas excludentes e hierarquizantes do sistema de gênero. Rever os marcos epistêmicos que organizam os nossos modos de compreensão é uma forma de construir outros modos de inteligibilidade sobre as vidas humanas, criando diferentes horizontes de inteligibilidade e de sociabilidade e combatendo as bases da violência de gênero (ou dos campos onde ela se gesta).

Os materiais didáticos são tecnologias que atuam na produção de um horizonte de vida e inclusão. A esfera pública dos materiais didáticos do MEC apresenta apenas as vidas heterossexuais no binarismo naturalizante macho-fêmea como vidas humanas. Essas vidas conformam comunidades morais invisíveis, e só são percebidas como tais quando se confrontam com a interpelação sobre a necessidade de representação de outras vidas, fora da ordem (hetero)sexual. Na vida escolar, a homofobia e o sexismo indicam que algumas vidas têm sido negadas ou diminuídas. Para pensar a representação política da vida humana é importante saber por que algumas vidas humanas são consideradas imprescindíveis e representáveis (que vivem em determinados corpos), e outras não (Butler, 2010). As vidas humanas, em sua vulnerabilidade constitutiva, necessitam de condições políticas para ser reconhecidas como genuinamente humanas. Se os materiais se mantêm na retórica heteronormativa, que condições de reconhecimento político as vidas fora dessa norma ou subalternizadas por ela podem ter?

A heteronorma regula o dizível e o representável, determinando quem será um sujeito e que experiências e modos de vida são legítimos (Butler, 2004). Se os materiais didáticos refletem um sistema cognitivo de privilégios de gênero e sexualidade, a política falha ao reproduzir 
a lógica que mantém as hierarquias. Para reconhecer a igualdade aos que têm sido historicamente subalternizados, é preciso redescrever a realidade, rever os marcos epistêmicos sobre os quais se apresentam os mundos, as identidades, os modos de vida. É necessário transformar a grade pela qual se olha e pela qual se aprende a pensar. É importante mostrar que outras configurações de gênero e sexualidade, fora do campo da heteronorma, são vidas possíveis.

Recebido em 11 de junho de 2012 Aprovado em 22 de novembro de 2012

\section{Notas}

1 Neste artigo, nosso posicionamento sobre a injúria se inspira nas análises de Didier Eribon (2008) sobre a constituição das subjetividades gays. Nesse contexto, a injúria é um mecanismo fundamental de vigilância das normas de gênero e, portanto, um modo de sujeição estruturante das vidas não heterossexuais (Eribon, 2008). A injúria é também um dispositivo de controle e moralização da feminilidade. Há outras possibilidades interpretativas no debate sobre sexualidade e discriminação.

2 "Fora da lei do gênero" é uma expressão de Kate Bornstein (1995) para designar todas as pessoas que não se enquadram no binarismo da diferença sexual, na heterossexualidade compulsória, ou em outras "leis do gênero".

3 Otermo episteme/epistêmico segue o mesmo campo de sentidos que tem sido usado por diversas pensadoras feministas e descoloniais, como Ochy Curiel Pichardo (2010), Beatriz Preciado (2002, 2008), que utiliza a expressão "epistemologias heterocentradas", Carrilo (2007), Walter Mignolo (2008), Nelson Maldonado-Torres (2009), que utiliza a expressão "racismo epistêmico", entre outras. De forma geral, episteme é um sistema de saber-poder em que certas representacões são autorizadas, e outras invisibilizadas, proibidas e invalidadas. Ou seja, trata-se de um modo de conhecer que estabelece quem pode conhecer e os domínios da vida que são tornados objeto de conhecimento.

4 As autoras deste artigo foram também autoras das pesquisas mencionadas. Trata-se das pesquisas Qual a diversidade sexual dos livros didáticos brasileiros? (executada entre 2007 e 2008, com financiamento do Programa Nacional de DST e Aids, do Ministério da Saúde, e do Escritório das Nações Unidas sobre Drogas e Crime, pela Anis - Instituto de Bioética, Direitos Humanos e Gênero), e da tese de doutorado Gênero e sexualidade na TV Escola: cartografias de um currículo (defendida em 2011). Salientamos que em outra pesquisa sobre livros didáticos de ensino religioso (estes não são distribuídos pelo MEC), encontramos resultados semelhantes (Diniz; Lionço; Carrião, 2010).

5 O Programa Nacional do Livro Didático é um dos programas de avaliação, seleção e distribuição de livros didáticos coordenados pelo Governo Federal. O MEC atua na apresentação de critérios para avaliação dos livros e no acompanhamento desta avaliação. Essa pesquisa, a que fazemos referência neste artigo, abrange o Programa Nacional do Livro Didático, o Programa Nacional do Livro Didático para o Ensino Médio, assim como o Programa Nacional Biblioteca na Escola. Usamos ao longo do artigo apenas o termo Programa Nacional do Livro Didático ao tratar destes programas para não sobrecarregar o texto com siglas e nomes extensos. A pesquisa qualitativa foi realizada com uma amostra dos livros didáticos mais distribuídos pelo PNLD e pelo PNLEM, em uso nos anos 2007 e 2008, bem como no universo de 25 dicionários distribuídos pelo PNLD 2006/Dicionários e pelo Programa Nacional Biblioteca da Escola (PNBE) de 1998. Foram selecionados livros de disciplinas que pudessem contemplar a temática da sexualidade no conteúdo programático. Em relação ao ensino fundamental, examinaram-se obras de alfabetização, português, ciências e história; quanto ao ensino médio, português, biologia e história. Note-se que o PNLD e o PNLEM não contam com 
Materiais Didáticos Escolares e Injustiça Epistêmica

uma memória permanente de todos os livros didáticos e dicionários distribuídos no país. Por isso, a coleta de dados adotou algumas estratégias para recuperação das obras e composição da amostra da pesquisa (Lionço; Diniz, 2009).

6 Foram analisados 61 programas catalogados como Orientação Sexual, em um universo de 75 , e 27 programas complementares, de um universo de 47 , selecionados pela temática de gênero ou sexualidade. A amostra dessa pesquisa de doutorado abarcou a programação da TV Escola desde sua formação, em 1996, até a programação divulgada pelo MEC em 2010, nos Guias de Programas (Oliveira, 2011). A pesquisa, portanto, faz uma análise que aponta para a história da programação de gênero e sexualidade da TV Escola. Alguns vídeos não constam da amostra devido à dificuldade da recuperação de todas as obras, dada a inexistência de acervo completo no MEC (onde não há quase nada), ou nas Secretarias de Educação (onde se encontra a maior parte das obras).

7 Homofobia deve ser entendida como um conceito guarda-chuva para representar a injúria, a violência, a perseguição contra as pessoas fora da lei heterossexual. Não deve se restringir à etimologia da palavra.

80 diferencialismo de gênero abarca, na programação da TVEscola, uma metafísica naturalista do gênero, a apresentação dos corpos em uma teleologia reprodutiva, a família heteropatriarcal, o dispositivo amoroso, a gravidez como destino da feminilidade, a moralização da feminilidade. Sobre os modos de racialização, paralelamente à branquidade figura a periferização da negritude e a morenidade nos audiovisuais analisados (Oliveira, 2011). Note-se que nenhuma categoria racial é um fato autoevidente, mas sim uma classificação cultural dos corpos situada em hierarquias sociais.

9 Dos 88 programas, apenas três discutem as não heterossexualidades de forma central. Desses três programas, dois politizam as discussões de gênero e sexualidade, e um se mantém na retórica biologizante. O ruído não heterossexista dos livros foi analisado por Fernando Pocahy, Rosana Oliveira e Thaís Imperatori (2009). Apenas um livro didático, em toda a amostra analisada, fez referência à diversidade sexual, mas destinou apenas uma página e meia a um debate marcado tanto pela timidez no desenvolvimento do tema quanto por um olhar heteronormativo (Pocahy; Oliveira; Imperatori, 2009).

10 Trata-se da série Alegria da vida, da grade de programas de Orientação Sexual da TV Escola.

11 Dos três programas da TVEscola que discutem de forma central as não heterossexualidades, dois apresentam de forma política as vidas lésbicas, gays, bissexuais e transgêneros: Zimbábue (que politiza as vidas não heterossexuais, especialmente a partir de um foco na experiência da lesbianidade) e Em outras palavras (que discute e politiza várias vidas fora da lei do gênero). No restante da programação, mantémse o marco heteronormativo, em que raras e eventuais inserções (politicamente corretas) da homossexualidade masculina ocorrem (Oliveira, 2011).

12 Gênero biológico parece ser a expressão mais adequada para falar do que se tem chamado de sexo, como discute Kate Bornstein (1995).

13 Alguns exemplos são os programas Sexualidadee adolescência, Meninos, a primeira vez, Perguntas que reprovam, Atração sexual, DST/AIDS e a série Alegria da vida, entre outros catalogados na área de Orientação Sexual (Oliveira, 2011).

14 As expressões bio-homem e bio-mulher, utilizadas por Beatriz Preciado (2008), não pretendem traçar diferenças entre o que é biológico e o que é sintético, pois a autora entende que tanto os corpos bio como os corpos trans são tecnicamente produzidos. O prefixo bio- visa a indicar uma produção corporal-política que assume uma aparência de natureza imutável e transcendental.

15 Neste texto, a utilização da expressão "fábula de gênero" une o sentido do termo utilizado por Butler (2003), que entende as identidades de gênero como efeitos de instituições e práticas, ao insight da análise de Emily Martin (1991), que com- 
para as representações construídas pelo discurso científico sobre o óvulo e o espermatozoide com um "romance baseado em estereótipos de masculinidade e feminilidade".

16 Alguns programas que exemplificam essa questão são Laços de menina, Marcos e Júlia, Uma vezinha só, Eu Tarzan, você Jane, Meninos, a primeira vez e O desenvolvimento do corpo humano, entre outros catalogados no campo Orientação Sexual (Oliveira, 2011).

17 Um dado curioso encontrado na pesquisa sobre livros didáticos de ensino religioso é que o tema do aborto está presente em um marco repressivo e dogmático de grave infração moral à vida.

18 Entre os audiovisuais com retóricas psicologizantes, exemplificamos alguns catalogados no campo de Orientação Sexual: Relações de gênero, Sexo: uma questão de qualidade de vida e A orientação sexual que se faz na escola.

19 Alguns exemplos de audiovisuais de Orientação Sexual com retóricas biologizantes: Alegria da vida, O desenvolvimento do corpo humano, Sexo, Eu Tarzan, você Jane e Reprodução humana.

20 Apesar da individualização e privatização do que se trata como sexualidade, os programas audiovisuais e os livros didáticos performam a heterossexualidade como uma prática pública. Diversas cenas e imagens mostram casais heterossexuais de mãos dadas, beijando-se e abraçando-se em locais públicos e privados. Mas não há cenas de casais não heterossexuais em 86 de 88 programas.

21 Beatriz Preciado $(2002,2008)$ discute como uma série de tecnologias farmacopolíticas atuou na fixação orgânica das diferenças de gênero, construindo nossa "natureza sexuada" no binarismo de gênero. Thomas Laqueur (2001) traça uma história de como emerge o discurso sobre a diferença sexual incomensurável, e portanto o diferencialismo de gênero heteronormativo. Numa historiografia em que analisa os livros de anatomia dos séculos XVIII eXIX, Thomas Laqueur (2001, p. 202) discute como os corpos masculinos e femininos são "artefatos cuja produção faz parte da história de sua época”. Compreendendo que não existe uma referência a um corpo puro, exclusivamente constatativa, que não seja também, em algum grau, uma formação adicional sobre aquele corpo, tais autores nos apontam para a contingência dos modos de inteligibilidade sobre os corpos e das normas de gênero que atuam na sua produção.

22 Aqui fazemos uma reapropriação do argumento de Sovik (2004) sobre a branquidade, transpondo-o para as questões de gênero.

\section{Referências}

BORNSTEIN, Kate. Gender Outlaw: on men, women and the rest of us. New York: Vintage Books, 1995.

BORRILLO, Daniel. A Homofobia. In: LIONÇO, Tatiana; DINIZ, Debora (Org.). Homofobia \& Educação: um desafio ao silêncio. Brasília: LetrasLivres; Ed. UnB, 2009. P. 15-46.

BUTLER, Judith. Problemas de Gênero: feminismo e subversão da identidade. Rio de Janeiro: Civilização Brasileira, 2003.

BUTLER, Judith. Deshacer el Género. Buenos Aires: Paidós, 2004.

BUTLER, Judith. Marcos de Guerra: las vidas lloradas. Buenos Aires: Paidós, 2010.

CARRILLO, Jesus. Entrevista com Beatriz Preciado. Cadernos Pagu, Campinas, n. 28, jun. 2007. Disponível em: <http://www.scielo.br/scielo.php?script=sci_ arttext\&pid=s0104-83332007000100016\&lng=en\&nrm=iso >. Acesso em: 4 nov. 2010 .

CURIEL PICHARDO, Rosa Ynés (Ochy). El Régimen Heterosexual de la Nación: un análisis antropológico lésbico-feminista de la Constitución Política de Colom- 
Materiais Didáticos Escolares e Injustiça Epistêmica

bia de 1991. Dissertação (Mestrado em Antropologia) - Facultad de Ciencias Humanas, Departamento de Antropología da Universidad Nacional de Colombia, Bogotá, 2010.

DINIZ, Debora. Antropologia e os Limites dos Direitos Humanos: o dilema moral de Tashi. In: NOVAES, Regina Reyes; LIMA, Roberto Kant de (Org.). Antropologia e Direitos Humanos: Prêmio ABA/FORD. Niterói: Eduff, 2001. P. 17-46.

DINIZ, Debora; LIONÇO, Tatiana; CARRIÃO, Vanessa. Laicidade e Ensino Religioso no Brasil. Brasília: Unesco; LetrasLivres: Ed. UnB, 2010.

ERIBON, Didier. Reflexões Sobre a Questão Gay. Rio de Janeiro: Companhia de Freud, 2008.

JUNQUEIRA, Rogério. Currículo Heteronormativo e Cotidiano Escolar Homofóbico. Espaço do Currículo, v. 2, n. 2, p. 208-230, set. 2009/mar. 2010.

LAQUEUR, Thomas. Inventando o Sexo. Rio de Janeiro: Relume Dumará, 2001.

LIONÇO, Tatiana; DINIZ, Debora (Org.). Homofobia \& Educação: um desafio ao silêncio. Brasília: LetrasLivres; Ed. UnB, 2009.

LOURO, Guacira Lopes. Pedagogias da sexualidade. In: LOURO, Guacira Lopes (Org.). O Corpo Educado: pedagogias da sexualidade. Belo Horizonte: Autêntica, 2000. P. 7-34

MALDONADO-TORRES, Nelson. A Topologia do Ser e a Geopolítica do Conhecimento: modernidade, império e colonialidade. In: SOUSA SANTOS, Boaventura de; MENESES, Maria Paula (Org.). Epistemologias do Sul. Coimbra: Almedina/ CES, 2009. P. 337-382.

MARTIN, Emily. The Egg and the Sperm: how science has constructed a romance based on stereotypical male-female roles. Signs: Journal of Women in Culture and Society, v. 16, n. 31, p. 485-501, 1991.

MIGNOLO, Walter D. A Opção Descolonial e o Significado de Identidade em Política. Caderno de Letras da UFF, Niterói, Dossiê: Literatura, língua e identidade, n. 34, p. 287-324, 2008.

OLIVEIRA, Rosana Medeiros de. Gênero e Sexualidade na TV Escola: cartografias de um currículo. 2011. Tese (Doutorado em História) - Programa de Pós-Graduação em História, Universidade de Brasília, Brasília, 2011.

POCAHY, Fernando; OLIVEIRA, Rosana; IMPERATORI, Thaís. Cores e Dores do Preconceito: entre o boxe e o balé. In: LIONCO, Tatiana; DINIZ, Débora (Org.). Homofobia \& Educação: um desafio ao silêncio. Brasília: LetrasLivres; Ed. UnB, 2009. P. 115-132.

PRECIADO, Beatriz. Manifiesto Contra-Sexual. Madrid: Opera Prima, 2002.

PRECIADO, Beatriz. Testo Yonqui. Madrid: Espasa Calpe, 2008.

SOVIK, Liv. Aqui Ninguém é Branco: hegemonia branca e media no Brasil. In: WARE, Vron (Org.). Branquidade: identidade branca e multiculturalismo. Rio de Janeiro: Garamond, 2004. P. 363-386.

Rosana Medeiros de Oliveira é doutora em História e pós-doutoranda em Política Social na Universidade de Brasília.

E-mail: rosanamedeirosde@gmail.com

Debora Diniz é antropóloga, professora da Universidade de Brasília e pesquisadora da Anis - Instituto de Bioética, Direitos Humanos e Gênero.

E-mail:d.diniz@anis.org.br 